\title{
The Influence of a Lake-to-Lake Connection from Lake Huron on the Lake-Effect Snowfall in the Vicinity of Lake Ontario
}

\author{
CARrie E. LANG, ${ }^{\mathrm{a}, \mathrm{b}, \mathrm{g}}$ JessicA M. MCDONALD,${ }^{\mathrm{c}, \mathrm{h}}$ LAURIANA GAUdet, ${ }^{\mathrm{d}, \mathrm{i}}$ Dylan Doeblin, ${ }^{\mathrm{e}}$ \\ ERIN A. JONES, ${ }^{\mathrm{f}}$ AND NEIL F. LAIRD ${ }^{\mathrm{e}}$ \\ ${ }^{a}$ Department of Mathematics, State University of New York at Geneseo, Geneseo, New York \\ ${ }^{\mathrm{b}}$ Department of Geography, State University of New York at Geneseo, Geneseo, New York \\ ${ }^{c}$ Department of Atmospheric and Hydrologic Sciences, Saint Cloud State University, Saint Cloud, Minnesota \\ ${ }^{\mathrm{d}}$ Department of Atmospheric Science, Lyndon State College, Lyndonville, Vermont \\ ${ }^{\mathrm{e}}$ Department of Geoscience, Hobart and William Smith Colleges, Geneva, New York \\ ${ }^{\mathrm{f}}$ Department of Earth Sciences, Millersville University of Pennsylvania, Millersville, Pennsylvania
}

(Manuscript received 8 August 2017, in final form 26 April 2018)

\begin{abstract}
Lake-effect storms (LES) produce substantial snowfall in the vicinity of the downwind shores of the Great Lakes. These storms may take many forms; one type of LES event, lake to lake (L2L), occurs when LES clouds/snowbands develop over an upstream lake (e.g., Lake Huron), extend across an intervening landmass, and continue over a downstream lake (e.g., Lake Ontario). The current study examined LES snowfall in the vicinity of Lake Ontario and the atmospheric conditions during Lake Huron-to-Lake Ontario L2L days as compared with LES days on which an L2L connection was not present [i.e., only Lake Ontario (OLO)] for the cold seasons (October-March) from 2003/04 through 2013/14. Analyses of snowfall demonstrate that, on average, significantly greater LES snowfall totals occur downstream of Lake Ontario on L2L days than on OLO days. The difference in mean snowfall between L2L and OLO days approaches $200 \%$ in some areas near the Tug Hill Plateau and central New York State. Analyses of atmospheric conditions found more-favorable LES environments on L2L days relative to OLO days that included greater instability over the upwind lake, more near-surface moisture available, faster wind speeds, and larger surface heat fluxes over the upstream lake. Last, despite significant snowfalls on L2L days, their average contribution to the annual accumulated LES snowfall in the vicinity of Lake Ontario was found to be small (i.e., $25 \%-30 \%$ ) because of the relatively infrequent occurrence of L2L days.
\end{abstract}

\section{Introduction}

Lake-effect storms (LES) affect large populations in the snowbelt regions downstream of the Great Lakes of North America and occur as a cold air mass is modified while passing over one or more of the Great Lakes during the cold season (e.g., Peace and Sykes 1966). The heat and moisture fluxes from the lake surface lead to

\footnotetext{
${ }^{\mathrm{g}}$ Current affiliation: Climate and Society Program, Columbia University, New York, New York.

${ }^{\mathrm{h}}$ Current affiliation: Atmospheric Science Program, Texas Tech University, Lubbock, Texas.

${ }^{i}$ Current affiliation: Department of Atmospheric and Environmental Sciences, University at Albany, State University of New York, Albany, New York.
}

Corresponding author: Neil F. Laird, laird@hws.edu instability within the atmospheric boundary layer, typically within the first few kilometers of the lower troposphere. This instability aids the development of LES, creating a greater possibility for substantial snowfall (e.g., Lavoie 1972).

LES may take many forms; one type is a lake-to-lake (L2L) connection that occurs when LES clouds/snowbands develop over an upstream lake, extend across an intervening landmass, and continue over a downstream lake. The presence of an upstream lake establishing an L2L connection routinely occurs over different areas within the Great Lakes region, such as from Lake Superior to Lake Michigan or from Lake Huron to Lake Ontario (Rodriguez et al. 2007; Laird et al. 2017). Niziol et al. (1995) identified L2L situations as being an important issue that complicates the forecasting of LES evolution and snowfall. This complexity during L2L events results because LES over the downstream lake occur within a 
more heterogeneous air mass that is preconditioned with respect to mesoscale thermodynamics and dynamics by the upstream lake. In addition, the atmospheric conditions and air-surface interactions must be considered over a larger area. For example, Villani et al. (2017) found that an L2L connection, or a multilake connection as they called it, provided a greater tendency for LES snowbands over the downstream lake to extend inland for greater distances. In addition, Rose (2000) investigated an L2L event from Lake Michigan to Lake Erie using mesoscale model simulations and found that eliminating the presence of Lake Michigan 1) reduced the snowfall maximum by two-thirds, 2) reduced vertical ascent by one-half, and 3) decreased cloud depth by several hundred meters.

L2L connections can often exist within a larger mesoscale vortex circulation that is produced when more than two Great Lakes act in aggregate (e.g., Sousounis and Fritsch 1994), demonstrating that dynamic and thermodynamic processes range across several spatial and temporal scales during these situations (e.g., Sousounis and Mann 2000). As an example, Mann et al. (2002) found that a significant morphological change in Lake Michigan (downstream) LES snowbands could be attributed to LES conditions originating over Lake Superior (upstream) that were embedded within a lake-aggregate circulation encompassing a large portion of the Great Lakes region.

Using GOES visible satellite imagery, both Rodriguez et al. (2007) and Laird et al. (2017) examined the frequency of days with L2L cloud bands in the Great Lakes region. Days with L2L cloud bands originating over Lake Superior were the most common, followed by days with L2L cloud bands originating over Lake Huron (LH). Rodriguez et al. (2007) and Laird et al. (2017) found that of the days with $\mathrm{L} 2 \mathrm{~L}$ originating over $\mathrm{LH}$ about $34 \%$ and $44 \%$, respectively, had an established downstream connection with Lake Ontario (LO). Laird et al. (2017) determined that the number of L2L days with a connection from $\mathrm{LH}$ to $\mathrm{LO}$ ranged from 2 to 12 days per cold season. Although the occurrence of days with $\mathrm{L} 2 \mathrm{~L}$ has large interannual variation, individual cases can be impactful. Ballentine et al. (1998) described a mesoscale-modeling study of a January 1995 LES that produced over $150 \mathrm{~cm}$ of snowfall in areas near LO. They found that an L2L connection from $\mathrm{LH}$ increased the moisture fed into the LO snowband and helped to augment LES precipitation.

Snowfall in the Great Lakes region has been explored using a variety of approaches to address many scientific issues related to LES. Numerous studies have presented the spatial distribution of annual snowfall in the Great Lakes region to identify the areas that have a substantial contribution from LES (e.g., Muller 1966; Dewey 1975;
Jiusto and Kaplan 1972; Strommen and Harman 1978; Norton and Bolsenga 1993). Several additional studies have used an assortment of approaches to estimate the proportion that LES snowfall contributes to the annual snowfall for different areas (e.g., Eichenlaub 1970; Wilson 1977; Braham and Dungey 1984, 1995; Kelly 1986; Scott and Huff 1996). A number of other investigations have explored the diurnal variation of observed LES snowfall (e.g., Kristovich and Spinar 2005; Veals and Steenburgh 2015) or long-term trends of snowfall for locations within the Great Lakes region (e.g., Burnett et al. 2003; Ellis and Johnson 2004; Kunkel et al. 2009; Bard and Kristovich 2012; Hartnett et al. 2014). Many studies have also investigated how variations in environmental conditions (e.g., stability, wind direction and speed, and lake and air temperatures) influence LES development and intensity (e.g., Lavoie 1972; Dewey 1975; Hjelmfelt 1990; Laird et al. 2003; Wright et al. 2013), as well as the enhancing influence that terrain has on LES snowfall (e.g., Hjelmfelt 1992; Alcott and Steenburgh 2013; Veals and Steenburgh 2015; Minder et al. 2015; Campbell et al. 2016; Campbell and Steenburgh 2017).

Even though L2L LES can be reasonably monitored during their occurrence and the frequency of days with L2L has been explored through climatological analyses, there still remain substantial uncertainties regarding the influence that L2L connections have on snowfall totals and the influence that the upstream preconditioned thermodynamic and dynamic environments have on the physical and dynamic processes responsible for LES over the downstream lake. The current study explores the influence of L2L connections from LH to LO on LES snowfall in the vicinity of LO across 11 cold seasons and examines from a climatological viewpoint the atmospheric environments for days with an L2L connection.

\section{Data and methods}

The current study utilizes the LES events database developed by Laird et al. (2017) that examined archived GOES visible imagery to identify days with LES clouds in the North American Great Lakes region for the 17 cold seasons (October-March) of 1997/98 through 2013/14. Rodriguez et al. (2007) and Laird et al. (2017) defined an L2L connection as having temporally and structurally coherent LES cloud bands that extend from an upstream lake, across land, and over a downstream lake. Three cases with GOES visible satellite imagery are presented in Fig. 1 to show examples of L2L connections as evidenced by mesoscale cloud bands extending from $\mathrm{LH}$ to both over and downstream of LO. Situations in which an upstream lake may have modified the atmospheric environment and a connecting LES cloud or snowband 

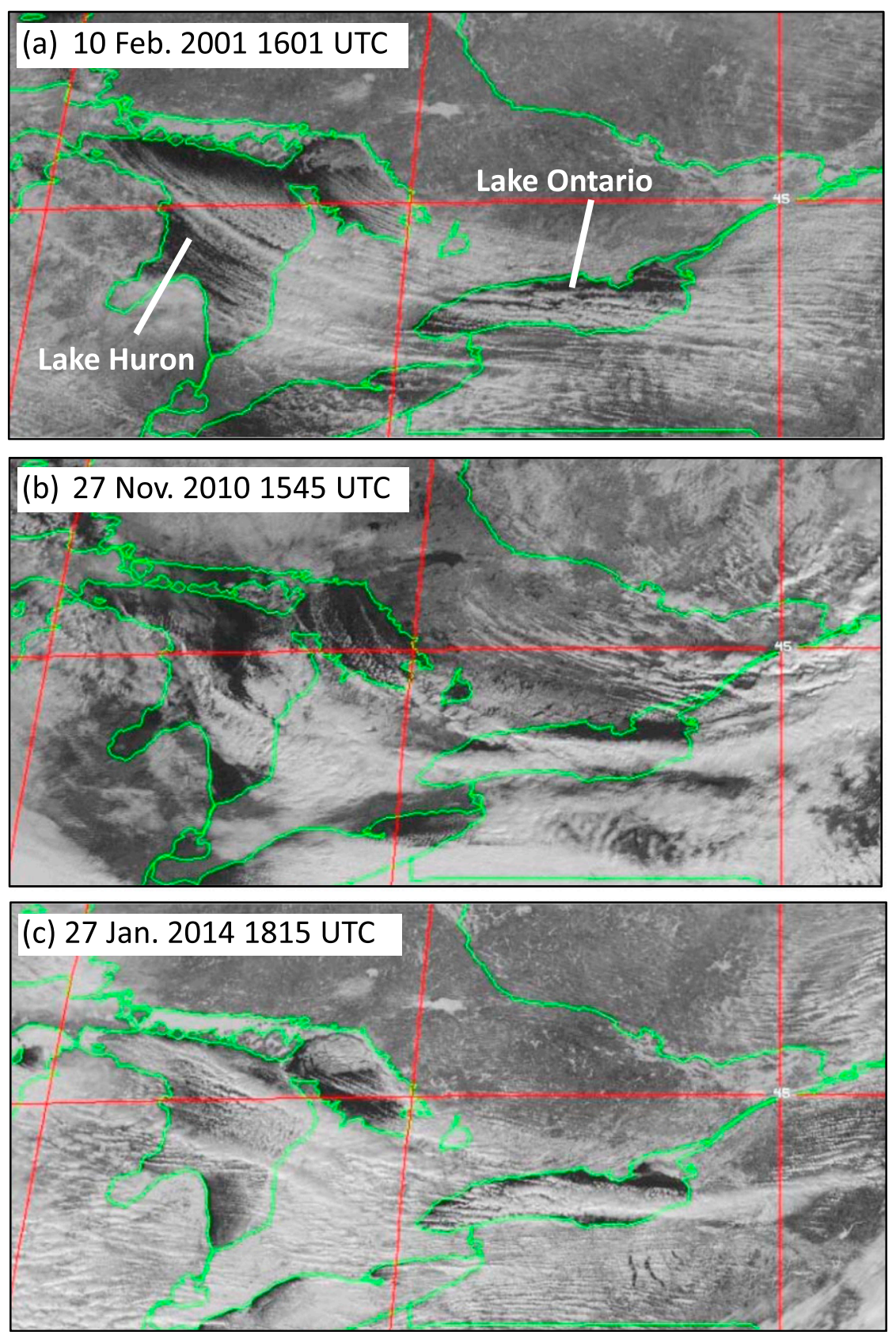

FIG. 1. GOES visible satellite images for three lake-effect cases of L2L cloudband connections from LH to LO.

was not observed in the GOES visible imagery were not considered by Laird et al. (2017) or Rodriguez et al. (2007) to be an L2L connection. The current study examines the 11 cold seasons from 2003/04 through 2013/14 because of the limited availability of complementary datasets. During this period, a total of 590 LES days occurred for LO. These included 62 days on which an L2L connection existed from LH to LO (mean days $\bar{N}=$
5.6 per season) and 528 days $(\bar{N}=48$ per season $)$ with LES over only LO (OLO days).

In addition, the occurrence of three primary types of LES morphologies was documented in the database produced by Laird et al. (2017), and the three are used in the current study. They include wind-parallel bands (WPB), shore-parallel bands (SPB), and unclear LES. WPB LES are primarily composed of horizontal roll 
convection and often result in widespread snowfall with smaller snowfall rates. SPB LES most often have a single primary snowband that produces localized snowfall with larger snowfall rates. Unclear LES exhibit mesoscale LES cloud and snowfall patterns that are not distinctly in any other LES morphology. The database includes information on single LES days on which more than one LES morphology existed over a lake because of the cloud pattern changing during a day or different LES cloud patterns being simultaneously present over separate areas of a lake. As an example, an LES day for LO could have had both SPB and WPB present over the lake. Of the 62 L2L days, SPB, WPB, and unclear LES occurred over LO on 30,33, and 15 days, respectively. Of the 528 OLO days, SPB, WPB, and unclear LES occurred on 242, 215, and 139 days, respectively.

Although Laird et al. (2017) provides an unparalleled database of identified LES days for the Great Lakes region, there are limitations on the information available within the database. GOES visible imagery was used for the study because of the limited spatial coverage of shallow LES systems from ground-based radars (Brown et al. 2007) and so as not to restrict the identification of LES activity, and their associated mesoscale circulations, only to periods of precipitation. The use of GOES visible imagery limited the identification of LES activity to daytime periods, likely resulting in an underestimate of the number of days having observed LES. Laird et al. (2017) identified 2123 days with one or multiple occurrences of LES clouds in the Great Lakes region during 17 cold seasons, but specific time periods (i.e., the span of hours) during each LES day with a particular LES morphology or L2L connection were not recorded, thereby limiting the database to daily information only.

As described in Barrett (2003) and Clow et al. (2012), the Snow Data Assimilation System (SNODAS) developed by the National Operational Hydrologic Remote Sensing Center (NOHRSC) provides daily, moderate-resolution $\left(1 \mathrm{~km}^{2}\right)$, gridded estimates of snow water equivalent and related snow parameters (e.g., snowfall, snow depth, sublimation, and snowmelt) for the contiguous United States available at daily time steps. SNODAS output is model output updated with observations, including 24-h snowfall accumulations at point locations collected primarily from the Cooperative Observer Program; the Community Collaborative Rain, Hail and Snow Network (CoCoRaHS); and National Weather Service spotter reports. Barrett (2003) and Carroll et al. (2006) describe the stepwise procedure for developing SNODAS products. First, temperature, wind, relative humidity, pressure, and precipitation analyses from the NOAA/National Centers for Environmental Prediction Rapid Refresh model (Benjamin et al. 2016) are ingested and downscaled from 13 to $1 \mathrm{~km}^{2}$. These data drive the NOHRSC Snow Model, which is a physically based, spatially distributed, energy-balance and mass-balance snow accumulation and ablation model run at $1-\mathrm{km}^{2}$ resolution. All available satellite, airborne, and ground-based snow observations are assimilated into the model and used to adjust model output by using a Newtonian nudging technique. SNODAS products have been archived for a period from September 2003 to the present. For this study, the driving parameter of solid precipitation (i.e., snowfall) was used to examine daily snowfall distributions prescribed in SNODAS to span a period from 0600 UTC on the LES day to 0600 UTC on the subsequent day. The uncertainty associated with SNODAS products is not documented, and the investigation of uncertainty in SNODAS products is beyond the scope of the current study. Along these lines, Barrett (2003) acknowledges that validation of SNODAS may be difficult because the datasets that would normally be used for validation are assimilated into the product already and therefore no truly independent validation dataset is readily available. Recent studies to determine uncertainty of SNODAS products have primarily focused on snow depth (e.g., Boniface et al. 2015; Wrzesien et al. 2017) because of the longer seasonal influence on regional hydrological conditions.

Only the days identified by Laird et al. (2017) as having had LES clouds occur over LO and also having SNODAS daily accumulated snowfall in the area downstream of LO were included in project analyses. Grids of daily accumulated snowfall from all L2L and OLO days across the 11 cold seasons were analyzed in ArcMap GIS software to examine 1) L2L and OLO mean snowfall distributions, 2) mean snowfall distributions within LES morphological groups, 3) percent differences between L2L and OLO mean snowfall, and 4) contributions to annual LES snowfall. Nonparametric analyses were conducted to determine the statistical significance of the difference between the mean L2L snowfall and the mean OLO snowfall at grid points corresponding to 13 cities across New York State. The Mann-Whitney $U$-test statistic was used to summarize the difference in mean rank numbers across two samples, specifically for comparison of L2L and OLO snowfall because of the nonnormally distributed daily snowfall amounts with the relatively small samples of L2L and OLO days. The two-tailed exact significance level was examined to determine statistical significance values at significance $p<0.01$ (i.e., 99\% confidence level). The SNODAS grid points nearest the locations of 13 cities across New York used for statistical comparison are shown on the GIS map analyses and included Rochester (ROC), Oswego (OSW), Lowville (LWV), Geneva (GNV), Ithaca (ITH), Gouveneur (GUV), Plattsburgh (PLT), Tupper 
Lake (TUP), Glens Falls (GFL), Utica (UTA), Oneonta (ONT), Binghamton (BGM), and Syracuse (SYR).

The current study used a composite approach to compare atmospheric conditions for days on which an $\mathrm{L} 2 \mathrm{~L}$ connection existed between LH and LO with days not having an observed L2L connection. These analyses utilized the North American Regional Reanalysis (NARR) dataset (Mesinger et al. 2006), the Hybrid Single-Particle Lagrangian Integrated Trajectory (HYSPLIT) model (Stein et al. 2015; Rolph et al. 2017), and Surface Data Hourly Global ("DS3505") meteorological station data from the National Centers for Environmental Information. The HYSPLIT model from the NOAA/Air Resources Laboratory was utilized to examine the backward trajectories of air parcels in place over LO during each LES day. For each LES day, the HYSPLIT model was run to produce a single 24-h backward trajectory from the NARR $32-\mathrm{km}$ archived output. The starting position for the air parcel over central LO had an altitude of $500 \mathrm{~m}$ above lake level, a latitude of $43.580^{\circ} \mathrm{N}$, and a longitude of $77.921^{\circ} \mathrm{W}$. The start date and time of 1700 UTC of the trajectories were used to correspond to the LES days identified by Laird et al. (2017). The HYSPLIT trajectories from the 590 LES days were then brought into ArcMap to analyze the parcel positions and spatial frequency during backward trajectories at 3-, 6-, 9- and 12-h times within a $1^{\circ}$ latitude $\times$ $1^{\circ}$ longitude grid that included the Great Lakes region.

\section{Seasonality of Lake Huron-to-Lake Ontario L2L events and OLO events}

The number of LES days for LO during the 11 cold seasons rapidly increases from October through December, remains high during December, January, and February, and then decreases into March (Fig. 2a). Although many fewer days with L2L occurred during the 11 cold seasons, the same intraseasonal pattern is present for the number of LH-to-LO L2L days. This resulted in the percent of LES days that were L2L days remaining relatively consistent from month to month. During the first five cold seasons (2003/04-2007/08) the total number of L2L and OLO days remained near the annual mean of LES days $(\bar{N}=$ 53.6 days per cold season; Fig. $2 \mathrm{~b}$ ). Later in the period of study the interannual variation was much larger, with over 70 LES days during the cold seasons of 2008/09 and 2013/14 whereas the cold seasons of 2009/10 and 2011/12 had fewer than 35 LES days.

\section{L2L and OLO snowfall}

Analyses of the SNODAS daily snowfall data show that, on average, over the 11 cold seasons L2L days have substantially greater snowfall totals than do OLO days
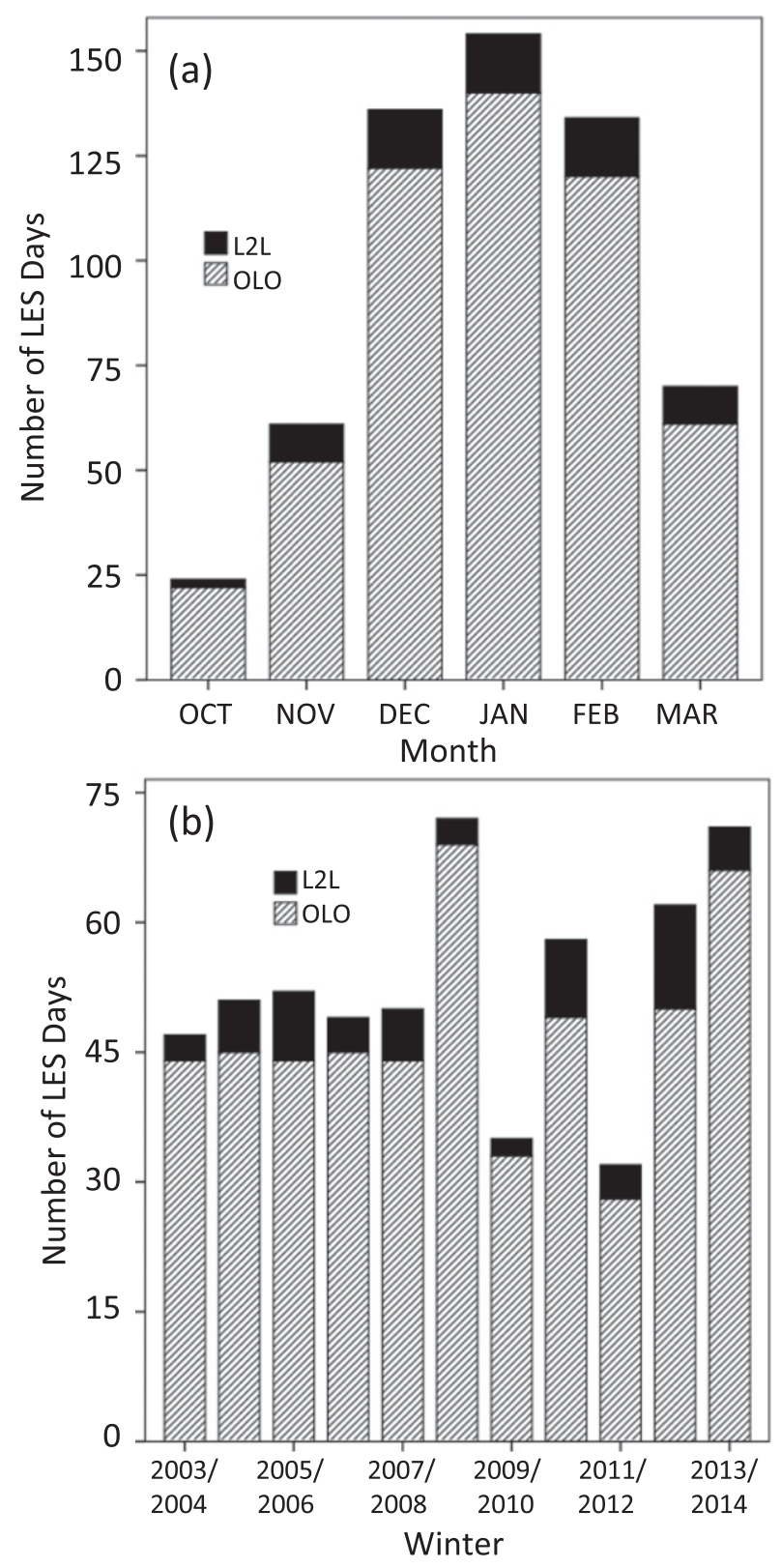

FIG. 2. (a) Monthly occurrence and (b) interannual variations of LH-to-LO L2L days and OLO days during cold seasons (OctoberMarch) from 2003/04 through 2013/14.

(Figs. 3a,b). The spatial distribution of mean LES snowfall downstream of LO, presented as snow liquid water equivalent (SLWE), has maxima located in the Tug Hill Plateau region for both L2L and OLO days. Mean snowfall has maximum values of $5.0-6.0 \mathrm{~mm}$ of SLWE from the $62 \mathrm{~L} 2 \mathrm{~L}$ days as compared with maximum values of $2.0-3.0 \mathrm{~mm}$ of SLWE from the 528 OLO days. Areas surrounding the Tug Hill Plateau and along the southern LO shoreline also received greater snowfall amounts on average during L2L days, with mean 

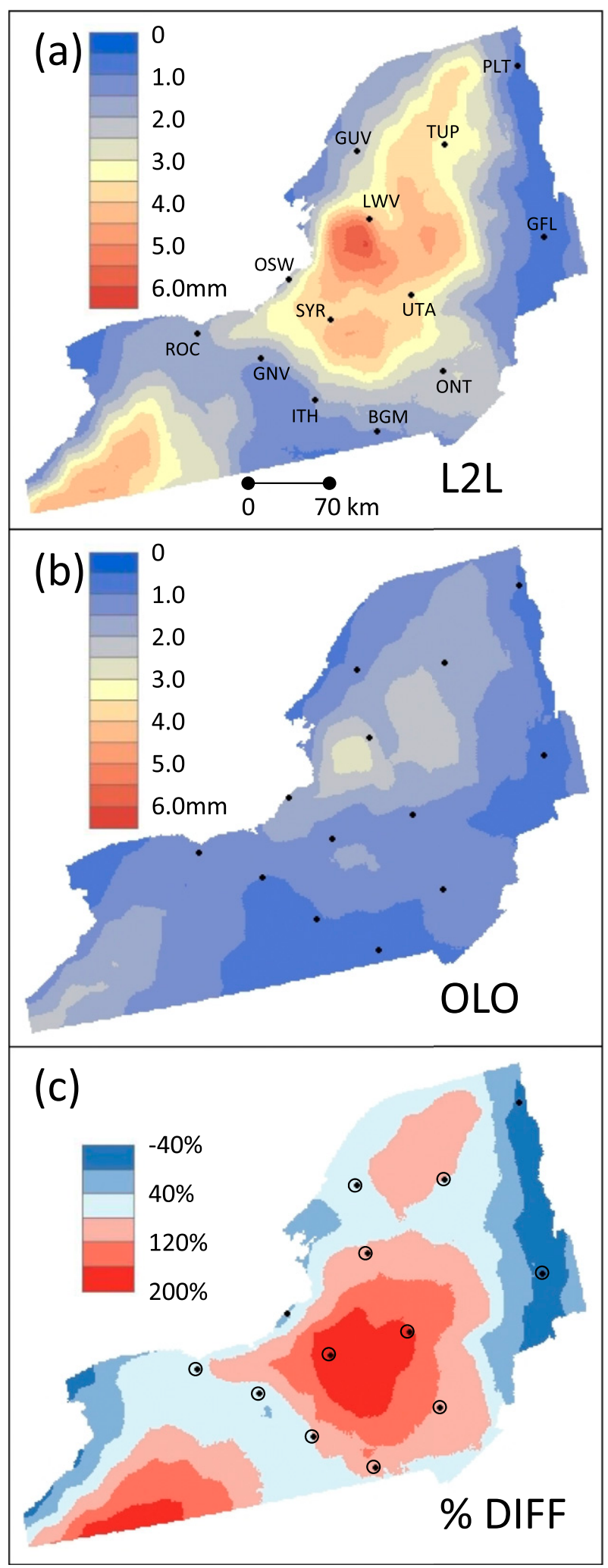

FIG. 3. Mean SLWE (mm) of (a) L2L days and (b) OLO days from the winters of 2003/04 through 2013/14. Also shown is the (c) percentage difference between mean SLWE for L2L days and values typically ranging from 2.0 to $5.0 \mathrm{~mm}$ of SLWE as compared with OLO mean values of $\leq 2.5 \mathrm{~mm}$ of SLWE. A region to the southeast of Lake Erie also shows substantial snowfall on both L2L and OLO days. With LES conditions typically widespread throughout the Great Lakes region during the cold season (Laird et al. 2017), it is reasoned that this snowfall region results from coincident LES systems on Lake Erie that are separate from LO systems rather than LES snowfall from LO snowbands on days with L2L or OLO.

The percent difference between the mean L2L snowfall and the mean OLO snowfall shows a maximum increase of $160 \%-200 \%$ located to the southeast of LO and the southern portion of the Tug Hill Plateau (Fig. 3c). Areas along the southern LO shoreline and into the central and northern Adirondack Mountains have increased snowfall of $40 \%-120 \%$ during L2L days. Nonparametric statistical analyses reveal that the difference between the L2L mean and the OLO mean is statistically significant at the $99 \%$ confidence level throughout most of the study area. Figure 3 a shows that 11 of the 13 city locations (i.e., all except Oswego and Plattsburgh) had significant differences in mean snowfall between L2L and OLO days, affirming the finding that L2L days produce significantly more snowfall than occurs on OLO days. Plattsburgh is well outside the LO snowbelt region and received minimal snowfall from LES systems. The statistical similarity of L2L and OLO mean snowfall amounts at Oswego suggests that this near-shoreline location is routinely impacted by all LES equally.

Niziol et al. (1995) stated that L2L LES bands were a hybrid of SPB and WPB and noted that L2L LES bands typically form over the upstream lake as an SPB. Analyses from the database associated with Laird et al. (2017) suggest that L2L can occur with differing forms of LES morphology over the downstream lake, however. The mean snowfall patterns resulting from different LES morphologies existing over LO for L2L days and OLO days across the 11 cold seasons were explored (Fig. 4). Three LES morphologies were investigated: SPB, WPB, and unclear, where unclear LES days exhibited mesoscale LES cloud patterns over LO that were not distinctly in any other LES morphology.

The mean snowfall on L2L days with SPB over LO had the greatest mean snowfall maxima of all LES

mean SLWE for OLO days. Open circles in (c) represent locations at which L2L and OLO SLWEs are statistically different with a $99 \%$ confidence level. Station identifiers, defined in the text, are provided in (a) for the statistical-testing locations shown in (c). 


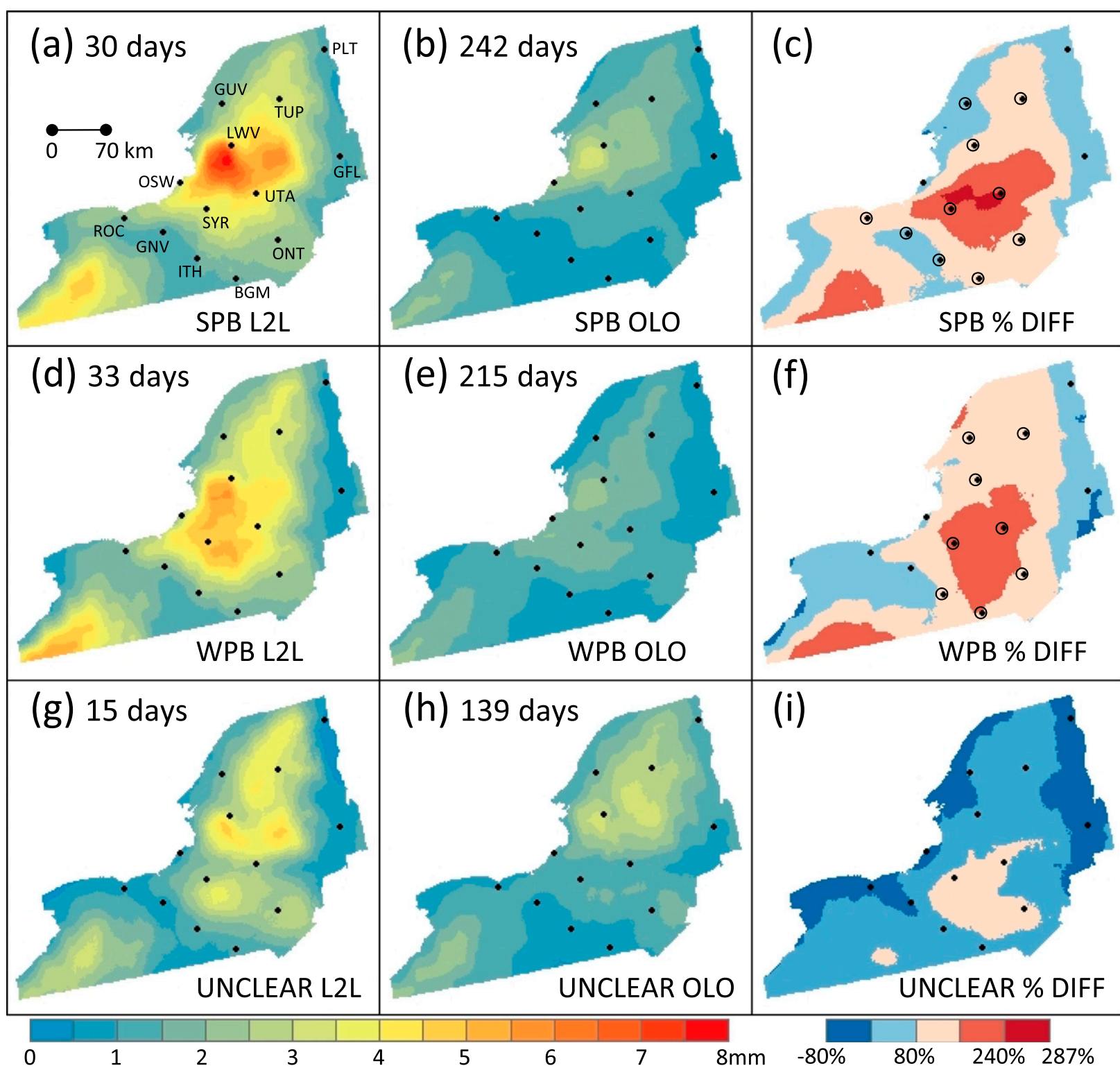

FIG. 4. Mean SLWE produced during L2L LES resulting from (a) SPB, (d) WPB, and (g) unclear LES systems over LO and during OLO LES resulting from (b) SPB, (e) WPB, and (h) unclear LES systems. Also shown is the percent difference between the L2L and OLO mean for (c) SPB, (f) WPB, and (i) unclear LES systems. The number of LES days in each sample is also shown. Open circles in (c) and (f) represent locations at which L2L and OLO SLWEs are statistically different with a $99 \%$ confidence level [there were no significant locations in (i)]. Station identifiers, defined in the text, are provided in (a) for the statistical-testing locations shown in (c), (f), and (i).

morphological types during L2L situations (Fig. 4a). This result is not surprising given that SPB events can often result in substantial snowfall totals (e.g., Wiggin 1950; Campbell et al. 2016). The largest values of mean snowfall on L2L days with SPB were widespread across the Tug Hill Plateau and central Adirondack Mountains. Maxima in mean SLWE on L2L days with WPB and unclear LES were more isolated and shifted farther southwestward relative to L2L SPB maxima (Figs. 4d,g). The largest values of L2L unclear LES days occurred along a west-to-east-oriented corridor east of LO and a south-to-north-oriented corridor over the "High Peaks" region of the Adirondack Mountains (Fig. 4g).

A comparison of L2L days with OLO days for each LES morphology clearly shows similar mean snowfall patterns were evident, but the mean SLWE for L2L days was always greater, with differences of $80 \%-160 \%$ over a large area downstream of LO for SPB, WPB, and unclear days (Figs. 4c,f,i). The largest differences were greater than $200 \%$ over an area to the southeast of LO 
for SPB and WPB days (Figs. 4c,f). For example, a mean SLWE of $>8.0 \mathrm{~mm}$ was located directly east of LO for L2L SPB days (Fig. 4a) whereas over the same area a mean SLWE of about $4.0 \mathrm{~mm}$ was present on OLO SPB days (Fig. 4b). The differences between the L2L and OLO mean snowfall for SPB and WPB days are statistically significant at the $99 \%$ confidence level across a large area downstream of LO (Figs. 4c,f). For SPB days, 10 of the 13 city locations had statistically significant differences between L2L and OLO days (shown by open circles at city locations in Fig. 4c). For WPB days, 8 of the 13 city locations had statistically significant differences between L2L and OLO days (Fig. 4f). The difference between the L2L and the OLO mean snowfall for unclear LES days was not statistically significant at the $99 \%$ confidence level (Fig. 4i).

Although mean snowfall on L2L days was found to be significantly greater than snowfall on OLO days, especially for SPB and WPB days, L2L snowfall does not contribute substantially to the annual LES snowfall in the vicinity of LO. Analyses of the mean annual accumulated SLWE from LES snowfall show that the Tug Hill Plateau and other regions in the vicinity of LO receive $\leq 42.1 \mathrm{~mm}$ per cold season from the small number of L2L days (Fig. 5a). Conversely, most regions near $\mathrm{LO}$ receive an average of $\geq 55.3 \mathrm{~mm}$ per cold season from the more frequent OLO days, with maxima on the Tug Hill Plateau upward of $130 \mathrm{~mm}$ (Fig. 5b). These analyses indicate that regions downstream of LO receive approximately $25 \%-30 \%$ of their annual LES snowfall from L2L days (Fig. 5c). Although the mean seasonal snowfall accumulation from L2L days is a relatively small contribution, it is noteworthy given the small number of L2L days, on average, per cold season.

\section{L2L and OLO atmospheric conditions}

During LES situations in the Great Lakes region, individual upstream lakes, or several lakes contributing in aggregate, have a pronounced influence on the development, evolution, and snowfall of LES systems over a downstream lake (e.g., Rose 2000; Sousounis and Mann 2000). The limited number of previous research studies on L2L events have provided good insight into these situations (e.g., Rodriguez et al. 2007), but there still remain many unexplored and important areas of research related to the atmospheric structure and characteristics of L2L connections and their influence on downstream LES convection and boundary layers. In this section, analyses using LES days for LO during 11 cold seasons provide a climatological examination of the atmospheric conditions that occur during LH-to-LO L2L days in comparison with OLO LES days.

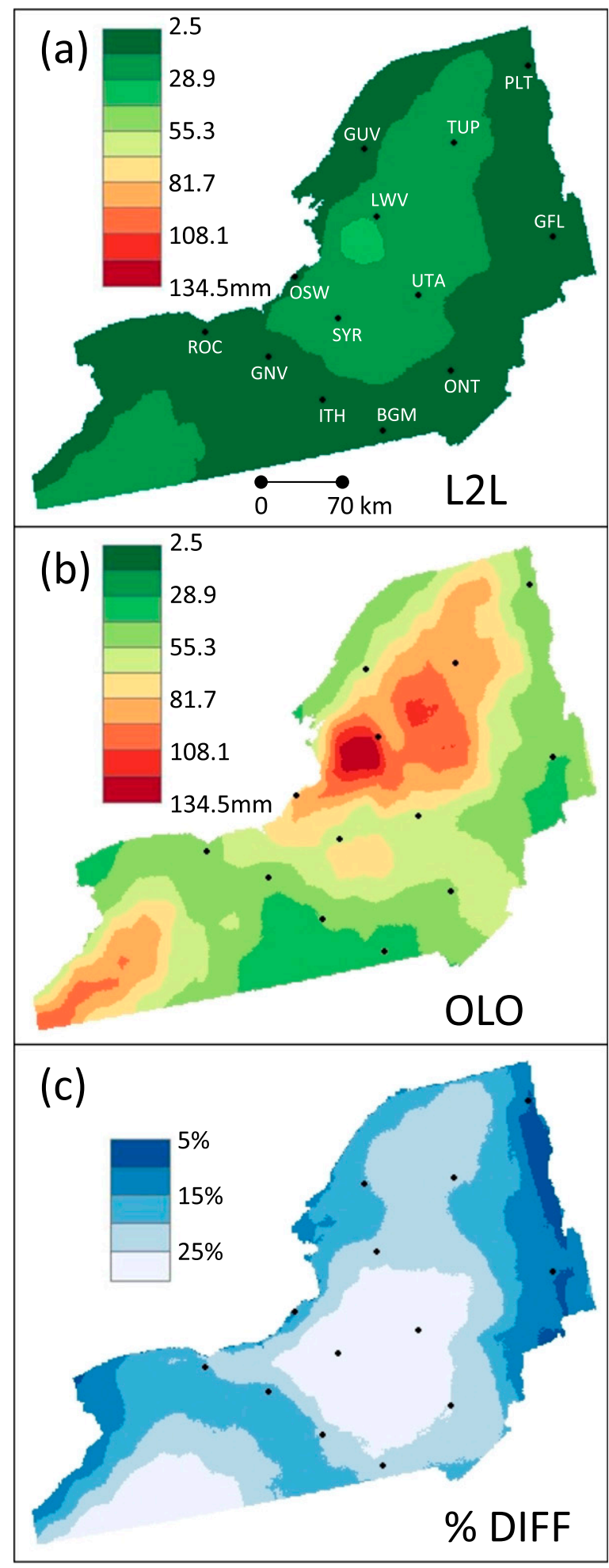

FIG. 5. Mean winter SLWE (mm) accumulations from (a) L2L and (b) OLO days during the winters of 2003/04-2013/14. Also shown is the (c) percentage difference (\%) between mean winter SLWE accumulations for L2L days and mean winter SLWE accumulations for OLO days. Station identifiers, defined in the text, are provided in (a) for specific city locations. 


\section{a. Surface-station analyses}

To examine the variation in upstream and downstream low-level atmospheric conditions on L2L and OLO days, hourly surface observations and NARR output at 1800 UTC were analyzed for the locations of Toronto, Ontario, Canada (TOR), and SYR. This early-afternoon time was chosen to represent conditions within the period observed with GOES visible satellite imagery used by Laird et al. (2017) to identify LES activity. On average, during LES days the 2-m air temperature at TOR was about $0.5^{\circ} \mathrm{C}$ colder than at SYR. The median temperature on L2L days was about $2^{\circ} \mathrm{C}$ colder for TOR than for SYR, and the median temperature on OLO days was about $1^{\circ} \mathrm{C}$ warmer for TOR relative to SYR (Fig. 6a). The Mann-Whitney $U$ test showed that the mean 2-m air temperatures were not statistically different when 1 ) comparing L2L days with OLO days for either TOR or SYR and 2) comparing TOR temperatures with SYR temperatures for L2L or OLO days.

The surface-850-hPa temperature-difference analyses that include TOR and SYR surface temperatures and NARR 850-hPa temperatures over each location, respectively (Fig. 6b), provide information about the atmospheric stability during L2L and OLO days. The surface-850-hPa temperature difference at the SYR and TOR locations was found to be statistically different at the 99\% confidence level when L2L days were compared with OLO days. Mean values for SYR were $10.4^{\circ} \pm 1.6^{\circ} \mathrm{C}$ and $8.9^{\circ} \pm 3.5^{\circ} \mathrm{C}$ for $\mathrm{L} 2 \mathrm{~L}$ and OLO days, respectively, and mean values for TOR were $11.6^{\circ} \pm 2.0^{\circ} \mathrm{C}$ and $9.1^{\circ} \pm 3.6^{\circ} \mathrm{C}$ for $\mathrm{L} 2 \mathrm{~L}$ and OLO days, respectively. The surface- $850-\mathrm{hPa}$ temperature difference at TOR for L2L days was significantly greater at the $99 \%$ confidence level when compared with SYR values. This difference in stability is mostly driven by the 850 -hPa temperatures over TOR being about $1.1^{\circ} \mathrm{C}$ colder than over SYR (Figs. 8e,f, described in more detail below). This may suggest that the air mass was less modified at $850 \mathrm{hPa}$ having traversed $\mathrm{LH}$ at TOR than having traversed $\mathrm{LH}$ and LO before arriving at SYR. On OLO days, the difference in stability between TOR and SYR was not statistically significant.

When compared, L2L and OLO surface wind speeds at TOR and at SYR were found to be statistically different at the $99 \%$ confidence level (Fig. 6c). Mean wind speeds for OLO days were $5.4 \pm 2.9 \mathrm{~m} \mathrm{~s}^{-1}$ and $6.2 \pm 3.1 \mathrm{~m} \mathrm{~s}^{-1}$ for SYR and TOR, respectively, as compared with the faster mean wind speeds for L2L days of $8.4 \pm 2.9 \mathrm{~m} \mathrm{~s}^{-1}$ and $8.0 \pm 3.2 \mathrm{~m} \mathrm{~s}^{-1}$ at SYR and TOR, respectively. Wind directions at SYR during L2L and OLO days were similar, with a direction from the west-northwest (WNW; Fig. 6d). Wind directions at TOR were significantly different at a 99\% confidence level when L2L and OLO days were compared. On L2L days, TOR wind directions were consistently from the WNW, and on OLO days TOR winds were more varied, primarily ranging from southwest to WNW. The mean wind directions during $\mathrm{L} 2 \mathrm{~L}$ days provide for a longer fetch for parcels moving across $\mathrm{LH}$ that would allow for greater airmass modification by surface heat fluxes. The faster mean wind speeds during $\mathrm{L} 2 \mathrm{~L}$ days contribute to two competing factors: 1) a shorter residence time for parcels moving over $\mathrm{LH}$, leading to less airmass modification, and 2) an enhancement of surface sensible and latent heat fluxes from the lake surface to the overlying atmosphere, resulting in greater airmass modification. In general, the longer fetch distances and greater surface latent heat fluxes over both LH and LO during L2L days when compared with OLO days would transfer a large amount of water vapor into the LES boundary layer. NARR composite analyses of low-level moisture in section $5 \mathrm{c}$ apparently indicate that the enhancement of surface fluxes on $\mathrm{L} 2 \mathrm{~L}$ days dominates over shorter residence times resulting from faster wind speeds (Figs. 8a,b, described in more detail below). This enhancement of moisture complemented by the greater instability would provide a more favorable atmospheric environment for LES cloudband development on L2L days than on OLO days.

\section{b. HYSPLIT backward-trajectory analyses}

HYSPLIT backward trajectories were used to examine further the environmental conditions on the identified $62 \mathrm{~L} 2 \mathrm{~L}$ days and 528 OLO days. Backward trajectories for each day were analyzed at the times of 3,6, 9, and $12 \mathrm{~h}$ prior to a parcel reaching the center of LO. The percentages of total parcels in $1^{\circ}$ latitude $\times 1^{\circ}$ longitude boxes at each time are used to represent the spatial concentration of parcel pathways (Fig. 7). When comparing the trajectories from all L2L days with those from all OLO days, the different flow patterns between these types of LES days are evident (scaled solid circles in Fig. 7). The spatial progression of points for L2L days demonstrates a distinct northwesterly concentration of trajectories located over LH and Georgian Bay at hours 3,6 , and 9 prior to the parcel arriving over central LO. In contrast, trajectories are more slowly distributed in all directions for OLO days, with a high concentration remaining over western $\mathrm{LO}$ at $3 \mathrm{~h}$ and a wide distribution across the eastern and central Great Lakes region, as well as southern Canada, at hours 6, 9, and 12.

Concentrations of backward-trajectory patterns were also examined with respect to individual LES morphology over LO (not shown). The pathways are similar on L2L SPB, WPB, and unclear LES days at 3, 6, and $9 \mathrm{~h}$, with parcels in a northwesterly flow passing over $\mathrm{LH}$. The distinction between L2L SPB and WPB trajectories becomes more evident at the 12-h L2L time period, with 

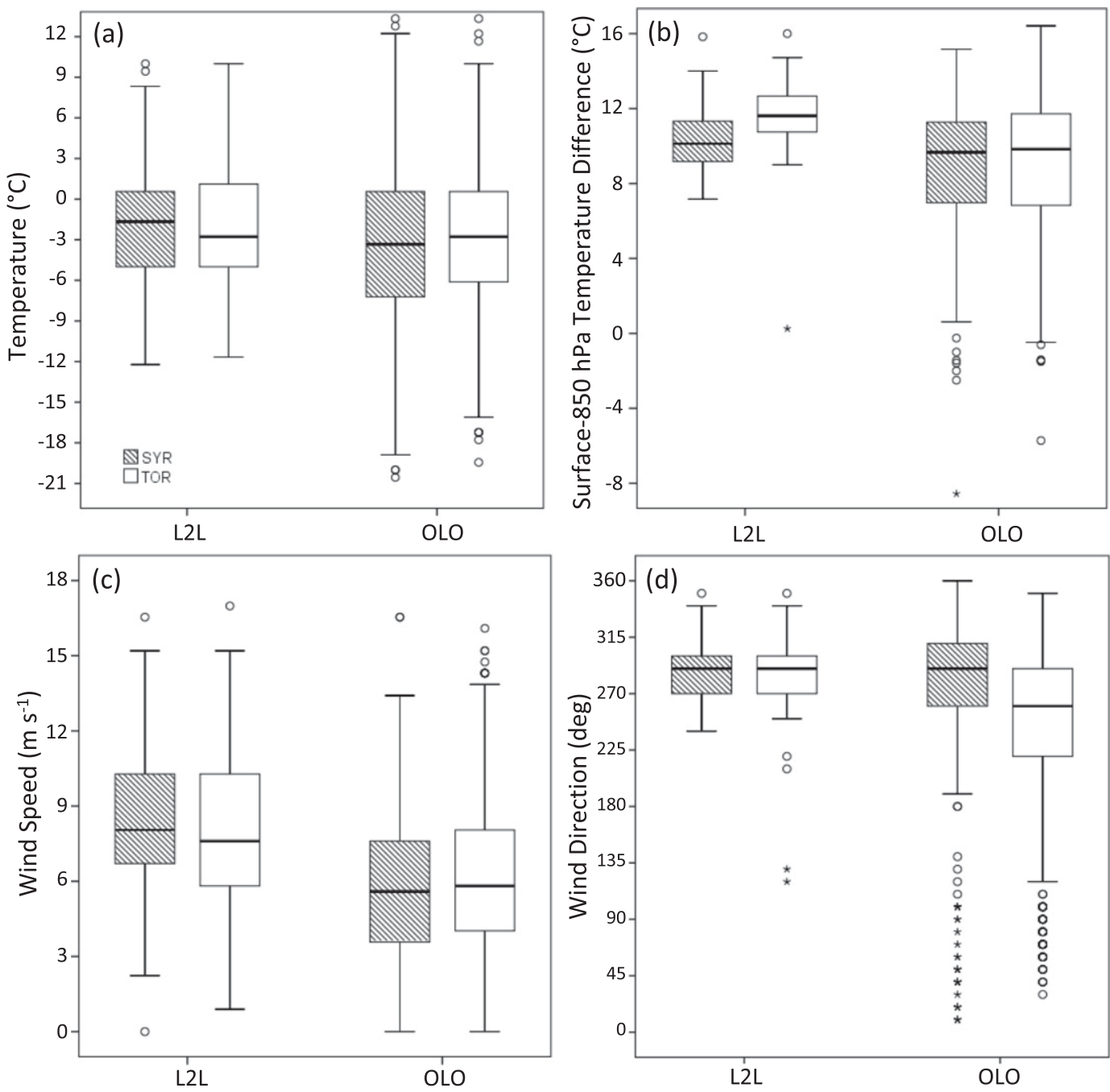

FIG. 6. Boxplots showing distributions on L2L and OLO days of (a) temperature $\left({ }^{\circ} \mathrm{C}\right.$ ), (b) surface-850-hPa temperature difference $\left({ }^{\circ} \mathrm{C}\right)$, (c) wind speed $\left(\mathrm{m} \mathrm{s}^{-1}\right)$, and $(\mathrm{d})$ wind direction $\left({ }^{\circ}\right)$ at $1800 \mathrm{UTC}$ for the TOR and SYR surface sites. The box represents the interquartile range (IQR). The line across the central portion of the box designates the sample median. Values that are greater than 3.0 times the IQR outside the box are denoted by asterisks and identified as extreme values. Values that are between 1.5 and 3.0 times the IQR outside the box are identified with open circles and represent outliers.

WPB trajectories distributed in a more northward direction and SPB trajectories located in the central and western Great Lakes region, suggesting that a second L2L connection to Lake Michigan or Lake Superior upstream of LH could be possible. In fact, 12 of the 30 L2L SPB days included in this study were identified in the database created by Laird et al. (2017) as having an LES L2L cloud band extending from either Lake Superior or Lake Michigan to LH and then extending over LO. Examination of OLO days indicates that the trajectories leading to SPB over LO are varied. Some trajectories follow west-to-east-oriented pathways, and others seem to indicate SPB development from land breezes, with some southward-oriented pathways. OLO WPB trajectories are concentrated to the north, as well as to the west during the 6-12-h time periods.

\section{c. NARR composite analyses}

Daily NARR data were used to examine mean composite atmospheric conditions for the identified $62 \mathrm{~L} 2 \mathrm{~L}$ days and 528 OLO days. Analyses of the 2-m temperature, 2-m specific humidity, sea level pressure, surface sensible and latent heat fluxes, 850 -hPa temperature, and $850-\mathrm{hPa}$ winds were examined (Figs. 8 and 9). The comparative composites are meant to serve as a supporting illustration of the potential atmospheric differences, but 

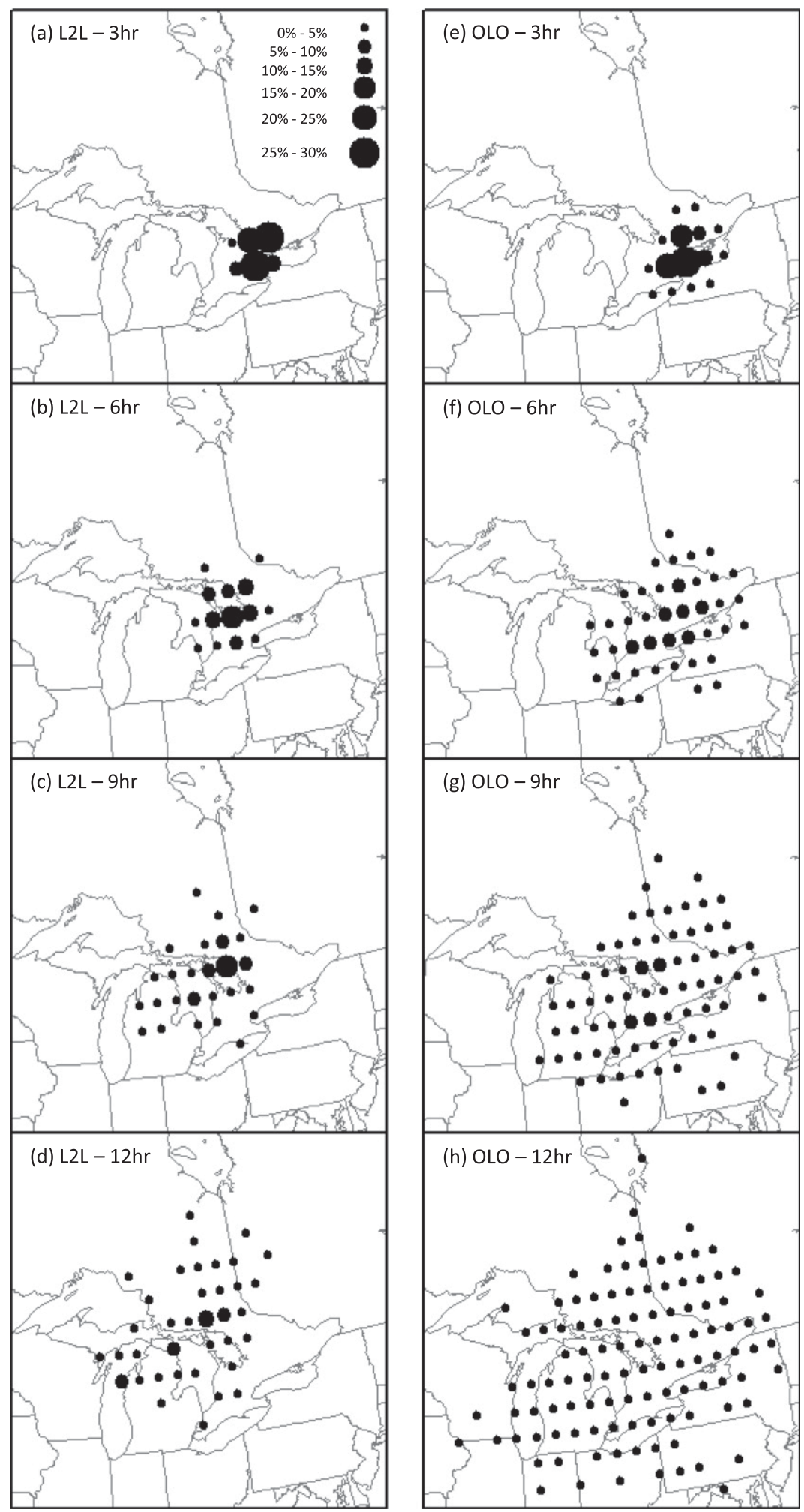

FIG. 7. Spatial frequency analyses of trajectories for (left) L2L and (right) OLO at (a),(e) 3, (b),(f) 6, (c),(g) 9, and (d),(h) $12 \mathrm{~h}$ prior to a parcel arriving at central $\mathrm{LO}$ on an LES day. 
they are not definitive, because statistical significance testing of the spatial fields was not performed for this study. The composite mean conditions for LH-to-LO L2L days show a noticeably different atmospheric situation in some variables when compared with OLO LES days. For example, L2L days tend to have greater amounts of atmospheric moisture over the entire eastern Great Lakes region, including maxima over Lakes Huron and Erie and a more expansive maximum over and downstream of LO, when compared with OLO LES days (Figs. 8a,b). This result suggests that LES occurring over LO on L2L days have a greater amount of nearsurface moisture available relative to situations in which a pronounced connection is not established with LH. For both L2L and OLO days, much colder surface temperatures over the southern portion of the Canadian province of Ontario establish a large temperature gradient along the northern boundary of the Great Lakes (Figs. 8c,d). The mean composite of 2-m air temperatures for L2L days shows warmer conditions over Lakes Huron, Michigan, Erie, and Ontario relative to those of OLO LES days, suggesting that individual lakes are contributing to greater airmass modification on L2L days.

The 850-hPa temperatures over LH are often nearly equivalent for both L2L and OLO days (Figs. 8e,f). This situation results in a larger difference between $850-\mathrm{hPa}$ temperatures and surface $(2 \mathrm{~m})$ temperatures over $\mathrm{LH}$ for $\mathrm{L} 2 \mathrm{~L}$ days than for OLO days, indicating a less stable lower troposphere over LH during L2L days. This configuration would provide a more favorable environment for LES convection to develop over LH. The magnitude of the surface-850-hPa temperature difference is similar between L2L and OLO days over LO since $850-\mathrm{hPa}$ temperatures over LO tend to be colder during OLO days. The NARR mean composites generally have very similar wind directions at $850 \mathrm{hPa}$ over the $\mathrm{LH}$ and LO region for both L2L and OLO days. Mean composites of 850-hPa wind speed tend to be faster for L2L days: nearly $12-14 \mathrm{~m} \mathrm{~s}^{-1}$ over LO as compared with winds on OLO days that are typically $8-10 \mathrm{~m} \mathrm{~s}^{-1}$ over LO.

In general, the magnitudes of sensible and latent heat fluxes over the western Great Lakes (Superior, Michigan, and Huron) are noticeably larger for L2L days than for OLO days (Figs. 9a-d). The mean NARR composite values of surface heat fluxes directed from lake to overlying air are typically $>150 \mathrm{~W} \mathrm{~m}^{-2}$. For the eastern lakes region (Erie and Ontario) the overlake surface fluxes are more similar between L2L and OLO days, with composite values of $50-150 \mathrm{~W} \mathrm{~m}^{-2}$. A large factor in producing the enhanced fluxes over LH on L2L days was the faster wind speeds when compared with those on OLO days, as evidenced by the greater sea level pressure gradient across the entire Great Lakes region (Figs. 8c,d) and surface observations at TOR and SYR (Fig. 6c).

The evidence in the NARR mean composites of decreased stability, enhanced atmospheric moisture, faster WNW winds, and the larger surface heat fluxes over LH during L2L days suggests that LH had a large impact on preconditioning the atmosphere upstream of LO. A period during which atmospheric conditions are favorable for LES over a large portion of the Great Lakes is a necessary and self-evident requirement for L $2 \mathrm{~L}$ to occur. Laird et al. (2017) found that nearly $75 \%$ of LES days in the Great Lakes region had multiple lakes experiencing LES, although the number of L2L connections is relatively small. Further analyses of the database developed by Laird et al. (2017) found that $100 \%$ of LH-to-LO L2L days during the 11 cold seasons examined for the current study had three or more Great Lakes experiencing LES (i.e., $10.8 \%$ on three lakes, $20.0 \%$ on four lakes, and $69.2 \%$ on five lakes). In comparison, LO was the only lake with LES during $11.7 \%$ of the 528 OLO days, and $76.6 \%$ of the OLO days had three or more Great Lakes with LE.

\section{d. Georgian Bay ice cover}

Cold seasons with a greater number of LES days did not have a larger number of L2L days (Fig. 2b). This result may suggest that ice cover on $\mathrm{LH}$ during particularly cold and/or active LES seasons-to be specific, ice cover on Georgian Bay, which is nearest to LO_limited the upstream preconditioning of the atmosphere during situations that would otherwise have had an observable L2L connection. Although substantial LES snowfall has still been observed to occur during cases in which extensive ice cover exists on a lake (Cordeira and Laird 2008), the presence of ice cover at high concentrations has been shown to greatly limit surface sensible and latent heat fluxes in LES situations (e.g., Gerbush et al. 2008; Wright et al. 2013). Great Lakes Environmental Research Laboratory ice-cover analyses were examined for all LES days (i.e., L2L and OLO). For purposes of this investigation, Georgian Bay ice coverage was grouped into two categories: 1) having an open-water area of $0 \%$ ice concentration or 2) being entirely covered with ice concentrations $>10 \%$. OLO and L2L days had regions of open water (i.e., $0 \%$ ice concentration) on Georgian Bay for $70.2 \%$ and $82.3 \%$ of days, respectively. This result suggests that L2L days were more likely to occur when Georgian Bay had less ice cover. Across all LES days in the current study, however, there exist substantial variations in other factors important for LES environments over both LH and LO (e.g., instability and winds). There is no doubt that ice cover on 

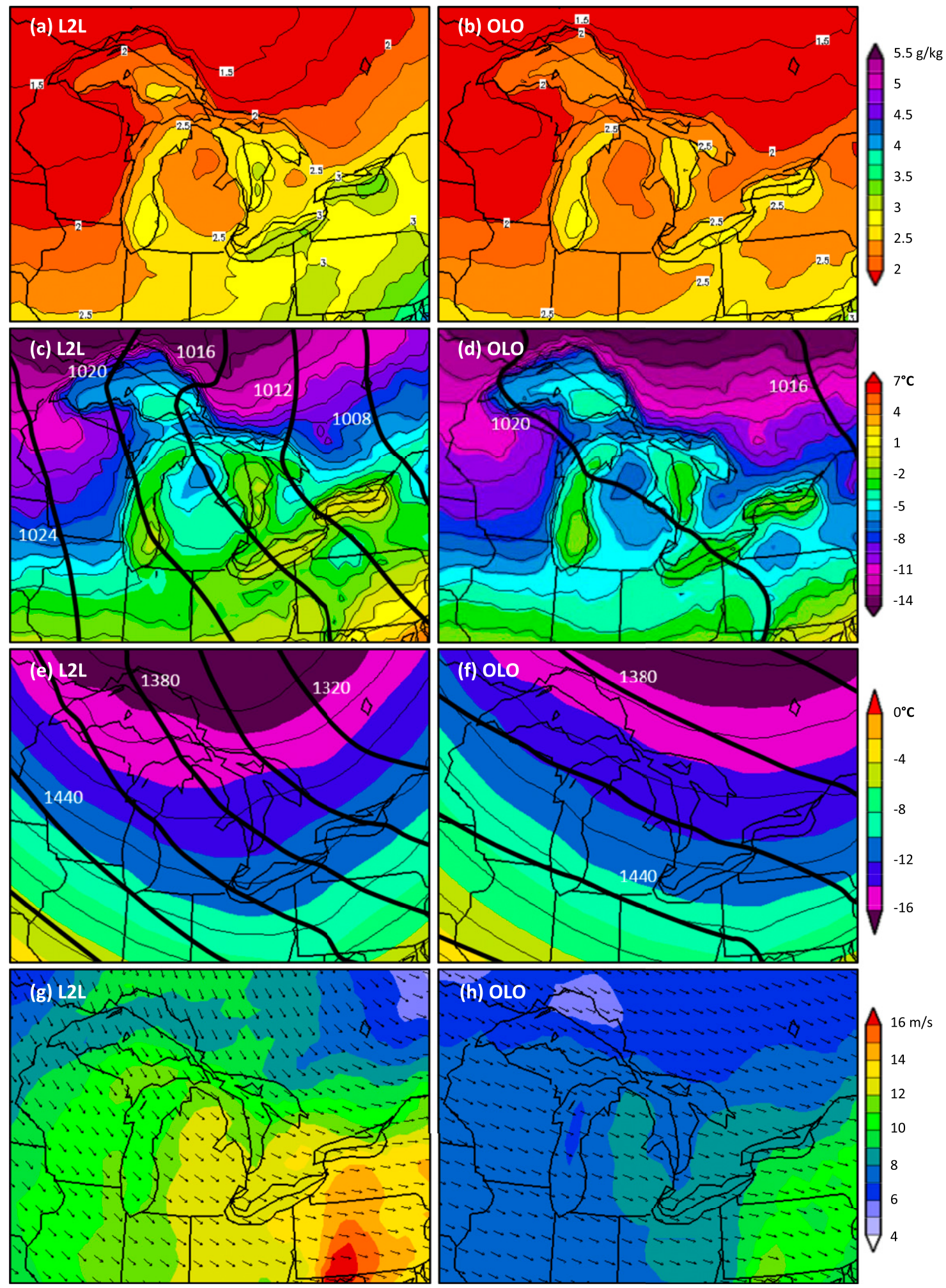

FIG. 8. Composite mean NARR analyses for (left) L2L and (right) OLO days during the cold seasons of 2003/04-2013/14 for (a),(b) 2-m specific humidity $\left(\mathrm{g} \mathrm{kg}^{-1}\right),(\mathrm{c}),(\mathrm{d}) 2$-m air temperature $\left({ }^{\circ} \mathrm{C}\right)$ and sea level pressure $(\mathrm{hPa}),(\mathrm{e}),(\mathrm{f}) 850-\mathrm{hPa}$ air temperature $\left({ }^{\circ} \mathrm{C}\right)$ and heights $(\mathrm{m})$, and $(\mathrm{g}),(\mathrm{h})$ 850-hPa wind direction vectors and contoured wind speed $\left(\mathrm{m} \mathrm{s}^{-1}\right)$. 

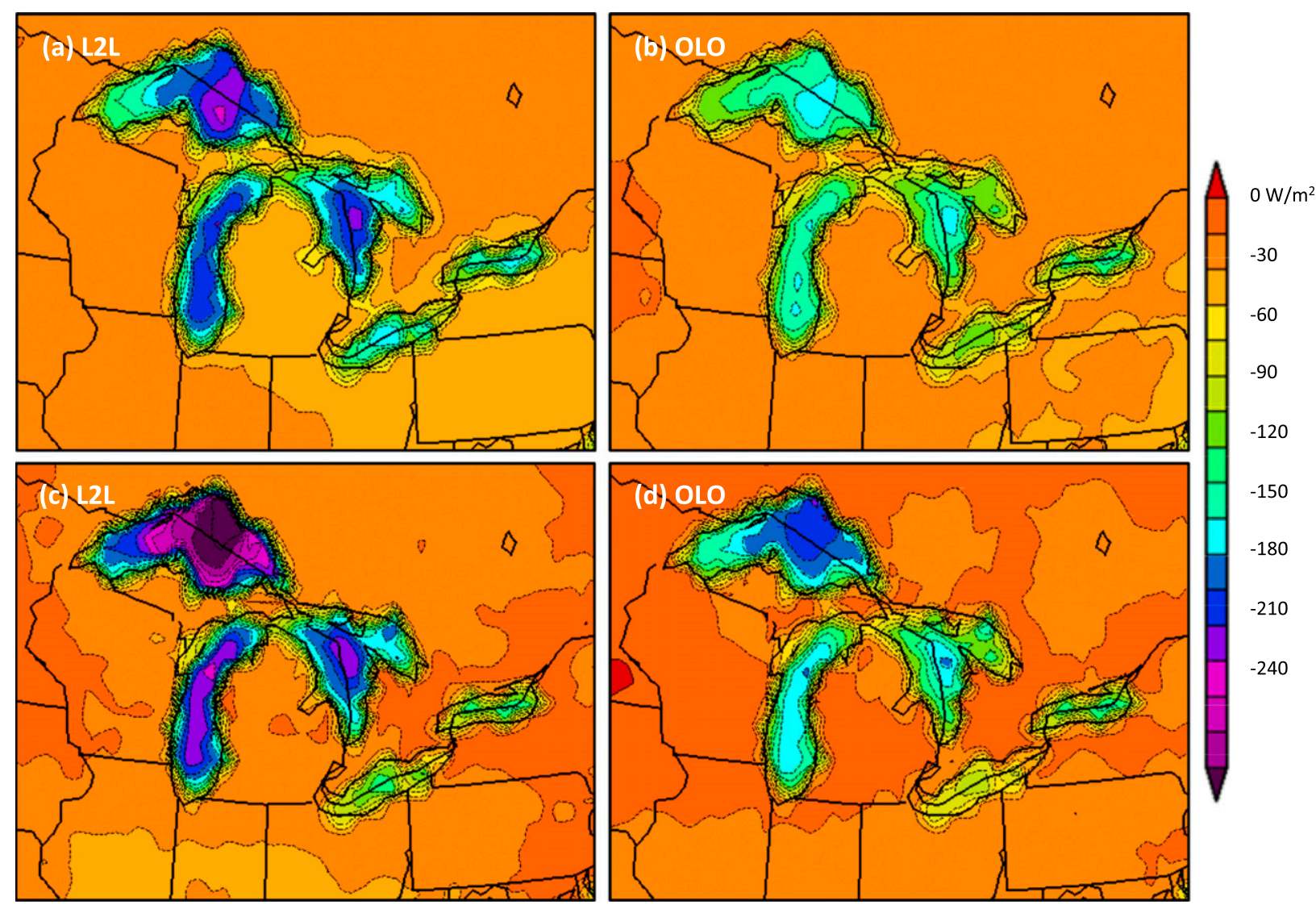

\section{$-30$}

$-60$

$-90$

FIG. 9. Composite mean NARR analyses for (left) L2L and (right) OLO LES days during the cold seasons of 2003/04-2013/14 for (a),(b) latent and (c),(d) sensible heat fluxes $\left(\mathrm{W} \mathrm{m}^{-2}\right)$ at the surface.

LH can influence the thermodynamic and dynamic structure of an L2L connection with LO and may contribute to severely limiting the presence of an L2L connection in certain situations. The completion of future research is necessary to understand better the influence of ice cover on LES, and specifically on L2L connections, across a variety of atmospheric conditions.

\section{Conclusions}

The current study employed a climatological approach using a variety of datasets to compare the snowfall in the vicinity of $\mathrm{LO}$ and atmospheric conditions on $\mathrm{L} 2 \mathrm{~L}$ and OLO days during the 11 cold seasons of 2003/04-2013/14. Analyses of snowfall downstream of LO showed that significantly greater LES snowfall totals occur on L2L days than on OLO days. The difference in mean snowfall between L2L and OLO days approaches $200 \%$ in some areas near the Tug Hill Plateau and central New York State. L2L days with SPB LES over LO make the greatest contribution to this difference; on average, they produce greater than $240 \%$ of the mean LES snowfall that occurs on OLO days for a region that includes Syracuse and Utica. L2L days with WPB LES were also found to contribute significantly to these differences by producing mean LES snowfall of greater than $160 \%$ relative to OLO days for the same region. In addition, because of the infrequent occurrence of L2L days, the average annual LES snowfall totals from L2L days were low, because the majority of LES snowfall in the vicinity of LO came from OLO days. Snowfall on L2L days was found to contribute less than $30 \%$ of the annual accumulated LES snowfall in the vicinity of LO.

Analyses of the atmospheric conditions during LO LES days showed that L2L days have, on average, more near-surface atmospheric moisture over the eastern Great Lakes region, greater instability over the upstream lake, faster wind speeds at the surface and $850 \mathrm{hPa}$, and larger surface heat fluxes over the upstream lake than do OLO days. In addition, backward trajectories on L2L days indicate a consistent linkage between upstream and downstream lakes, whereas much more varied backwardtrajectory pathways were found for OLO days. Although some backward trajectories for OLO days were positioned 
over $\mathrm{LH}$, the atmospheric conditions over $\mathrm{LH}$ on OLO days were found to be less favorable for LES, which would cause the development of LES over LO to rely mostly on the atmospheric conditions near the downstream lake.

Understanding the complexity of L2L situations and the impact that these events have on snowfall distributions remains difficult because of the multiscale interactions that span the synoptic scale, mesoscale, and microscale across a region of heterogeneous landscape and terrain. An important issue that previous studies have identified as influential to L2L days, and especially to the development and evolution of the LES over the downstream lake, is the structure and characteristics of the boundary layer (e.g., moisture transport and preexisting convergence zones) that develop over the upstream lake. In addition, NARR composites show some substantial differences in the SLP and 850-hPa height fields, with some evidence for a mean trough on the $\mathrm{L} 2 \mathrm{~L}$ days, with the location of this trough shifted eastward on OLO days. This possible difference in the synoptic-scale forcing of vertical motion between OLO and L2L days may also contribute to the identified precipitation differences, thereby complementing mesoscale and microscale forcing.

A comprehensive examination of these contributing factors and the specific influence of ice cover on the upstream lake for L2L situations was beyond the scope of the current study. This avenue of investigation, perhaps using analyses of specific case studies and numerical model simulations, would be a natural next step for future investigations to advance understanding of L2L connections and their influence on enhancement of snowfall near the downstream lake. Some research from the Ontario Winter Lake-effect Systems (OWLeS) field project (Kristovich et al. 2017) is moving our understanding of these issues forward, but research related to addressing the modification of the preconditioned upstream lake boundary layer over an intervening landmass with an established stable atmospheric boundary layer is necessary, as is further investigation of the thermodynamic and dynamic influence that the remnant upstream lake boundary layer has on the development of downstream LES systems during varied L2L situations.

Acknowledgments. Authors Lang, McDonald, and Gaudet conducted this research as undergraduate students and at the time of this writing are pursuing graduate studies at the respective institutions listed in the title-page footnotes. This research was conducted during the 2014-17 Undergraduate Summer Research Programs at Hobart and William Smith (HWS) Colleges and was supported by National Science Foundation Research Grant AGS-1258548 and the HWS Provost's Office. We gratefully acknowledge contributions from beneficial conversations with Dr. Nicholas D. Metz of HWS, Drs. Jason Cordeira and Eric Hoffman of Plymouth State University, Michael Evans and Michael Jurewicz of the U.S. National Weather Service Forecast Office in Binghamton, Ross Lazear of the University at Albany, and Dr. David Kristovich of the Illinois State Water Survey. We appreciate the IT/GIS support that we received from Robert Beutner at HWS. The NCEP NARR data were obtained online from the NOAA/ OAR/ESRL Physical Science Division (http://www.esrl. noaa.gov/psd/). The authors gratefully acknowledge the NOAA/Air Resources Laboratory for providing the HYSPLIT transport and dispersion model used in this publication. The NOAA Great Lakes Ice Atlas and archived analyses were provided by the NOAA Great Lakes Environmental Research Laboratory.

\section{REFERENCES}

Alcott, T. I., and W. J. Steenburgh, 2013: Orographic influences on a Great Salt Lake-effect snowstorm. Mon. Wea. Rev., 141, 2432-2450, https://doi.org/10.1175/MWR-D-12-00328.1.

Ballentine, R. J., A. J. Stamm, E. E. Chermack, G. P. Byrd, and D. Schleede, 1998: Mesoscale model simulation of the 4-5 January 1995 lake-effect snowstorm. Wea. Forecasting, 13, 893-920, https://doi.org/10.1175/1520-0434(1998)013<0893: MMSOTJ $>2.0 . \mathrm{CO} ; 2$.

Bard, L., and D. A. R. Kristovich, 2012: Trend reversal in Lake Michigan contribution to snowfall. J. Appl. Meteor. Climatol., 51, 2038-2046, https://doi.org/10.1175/JAMC-D-12-064.1.

Barrett, A., 2003: National Operational Hydrologic Remote Sensing Center Snow Data Assimilation System (SNODAS) products at NSIDC. NSIDC Special Rep. 11, 19 pp., https://nsidc.org/sites/ nsidc.org/files/files/nsidc_special_report_11.pdf.

Benjamin, S. G., and Coauthors, 2016: A North American hourly assimilation and model forecast cycle: The Rapid Refresh. Mon. Wea. Rev., 144, 1669-1694, https://doi.org/10.1175/ MWR-D-15-0242.1.

Boniface, K., J. J. Braun, J. L. McCreight, and F. G. Nievinski, 2015: Comparison of snow data assimilation system with GPS reflectometry snow depth in the western United States. Hydrol. Processes, 29, 2425-2437, https://doi.org/10.1002/hyp.10346.

Braham, R. R., Jr., and M. J. Dungey, 1984: Quantitative estimates of the effect of Lake Michigan on snowfall. J. Climate Appl. Meteor., 23, 940-949, https://doi.org/10.1175/1520-0450(1984) $023<0940$ :QEOTEO $>2.0$.CO;2.

__, and —_, 1995: Lake-effect snowfall over Lake Michigan. J. Appl. Meteor., 34, 1009-1019, https://doi.org/10.1175/ 1520-0450(1995)034<1009:LESOLM>2.0.CO;2.

Brown, R. A., T. A. Niziol, N. R. Donaldson, P. I. Joe, and V. T. Wood, 2007: Improved detection using negative elevation angles for mountaintop WSR-88Ds. Part III: Simulations of shallow convective activity over and around Lake Ontario. Wea. Forecasting, 22, 839-852, https://doi.org/10.1175/WAF1019.1.

Burnett, A. W., M. E. Kirby, H. T. Mullins, and W. P. Patterson, 2003: Increasing Great Lake-effect snowfall during the twentieth century: 
A regional response to global warming? J. Climate, 16, 35353542, https://doi.org/10.1175/1520-0442(2003)016<3535: IGLSDT $>2.0 . \mathrm{CO} ; 2$.

Campbell, L. S., and W. J. Steenburgh, 2017: The OWLeS IOP2b lake-effect snowstorm: Mechanisms contributing to the Tug Hill precipitation maximum. Mon. Wea. Rev., 145, 2461-2478, https://doi.org/10.1175/MWR-D-16-0461.1.

, P. G. Veals, T. W. Letcher, and J. R. Minder, 2016: Lake-effect mode and precipitation enhancement over the Tug Hill Plateau during OWLeS IOP2b. Mon. Wea. Rev., 144, 1729-1748, https://doi.org/10.1175/MWR-D-15-0412.1.

Carroll, T. R., D. W. Cline, C. Olheiser, A. Rost, A. Nilsson, G. Fall, C. Bovitz, and L. Li, 2006: NOAA's national snow analyses. Proc. 74th Annual Meeting of the Western Snow Conf., Las Cruces, NM, Western Snow Conference, 31-43, https://westernsnowconference.org/biblio/export/rtf/837.

Clow, D. W., L. Nanus, K. L. Verdin, and J. Schmidt, 2012: Evaluation of SNODAS snow depth and snow water equivalent estimates for the Colorado Rocky Mountains, USA. Hydrol. Processes, 26, 2583-2591, https://doi.org/10.1002/hyp.9385.

Cordeira, J. M., and N. F. Laird, 2008: The influence of ice cover on two lake-effect snow events over Lake Erie. Mon. Wea. Rev., 136, 2747-2763, https://doi.org/10.1175/2007MWR2310.1.

Dewey, K. F., 1975: The prediction of Lake Huron lake-effect snowfall systems. J. Appl. Meteor., 14, 3-7, https://doi.org/ 10.1175/1520-0450(1975)014<0003:TPOLHL>2.0.CO;2.

Eichenlaub, V. L., 1970: Lake effect snowfall to the lee of the Great Lakes: Its role in Michigan. Bull. Amer. Meteor. Soc., 51, 403-412, https:// doi.org/10.1175/1520-0477(1970)051<0403:LESTTL>2.0.CO;2.

Ellis, A. W., and J. J. Johnson, 2004: Hydroclimatic analysis of snowfall trends associated with the North American Great Lakes. J. Hydrometeor., 5, 471-486, https://doi.org/10.1175/ 1525-7541(2004)005<0471:HAOSTA > 2.0.CO;2.

Gerbush, M. R., D. A. R. Kristovich, and N. F. Laird, 2008: Mesoscale boundary layer and heat flux variations over pack icecovered Lake Erie. J. Appl. Meteor. Climatol., 47, 668-683, https://doi.org/10.1175/2007JAMC1479.1.

Hartnett, J. J., J. M. Collins, M. A. Baxter, and D. P. Chambers, 2014: Spatiotemporal snowfall trends in central New York. J. Appl. Meteor. Climatol., 53, 2685-2697, https://doi.org/ 10.1175/JAMC-D-14-0084.1.

Hjelmfelt, M. R., 1990: Numerical study of the influence of environmental conditions on lake-effect snowstorms over Lake Michigan. Mon. Wea. Rev., 118, 138-150, https://doi.org/ 10.1175/1520-0493(1990)118<0138:NSOTIO $>2.0$.CO;2.

_ 1992: Orographic effects in simulated lake-effect snowstorms over Lake Michigan. Mon. Wea. Rev., 120, 373-377, https:// doi.org/10.1175/1520-0493(1992)120<0373:OEISLE >2.0.CO;2.

Jiusto, J. E., and M. L. Kaplan, 1972: Snowfall from lake-effect storms. Mon. Wea. Rev., 100, 62-66, https://doi.org/10.1175/ 1520-0493(1972)100<0062:SFLS $>2.3$.CO;2.

Kelly, R. D., 1986: Mesoscale frequencies and seasonal snowfalls for different types of Lake Michigan snow storms. J. Climate Appl. Meteor., 25, 308-312, https://doi.org/10.1175/1520-0450(1986) $025<0308$ :MFASSF $>2.0 . \mathrm{CO} ; 2$.

Kristovich, D. A. R., and M. L. Spinar, 2005: Diurnal variations in lake-effect precipitation near the western Great Lakes. J. Hydrometeor., 6, 210-218, https://doi.org/10.1175/JHM403.1. , and Coauthors, 2017: The Ontario Winter Lake-Effect Systems field campaign: Scientific and educational adventures to further our knowledge and prediction of lake-effect storms. Bull. Amer. Meteor. Soc., 98, 315-332, https:// doi.org/10.1175/BAMS-D-15-00034.1.
Kunkel, K. E., L. Ensor, M. Palecki, D. Easterling, D. Robinson, K. G. Hubbard, and K. Redmond, 2009: A new look at lakeeffect snowfall trends in the Laurentian Great Lakes using a temporally homogeneous data set. J. Great Lakes Res., 35, 23-29, https://doi.org/10.1016/j.jglr.2008.11.003.

Laird, N. F., D. A. R. Kristovich, and J. E. Walsh, 2003: Idealized model simulations examining the mesoscale structure of winter lake-effect circulations. Mon. Wea. Rev., 131, 206-221, https:// doi.org/10.1175/1520-0493(2003)131<0206:IMSETM>2.0.CO;2.

— N. D. Metz, L. Gaudet, C. Grasmick, L. Higgins, C. Loeser, and D. A. Zelinsky, 2017: Climatology of cold season lakeeffect cloud bands for the North American Great Lakes. Int. J. Climatol., 37, 2111-2121, https://doi.org/10.1002/joc.4838.

Lavoie, R. L., 1972: A mesoscale numerical model of lake-effect storms. J. Atmos. Sci., 29, 1025-1040, https://doi.org/10.1175/ 1520-0469(1972)029<1025:AMNMOL>2.0.CO;2.

Mann, G. E., R. B. Wagenmaker, and P. J. Sousounis, 2002: The influence of multiple lake interactions upon lake-effect storms. Mon. Wea. Rev., 130, 1510-1530, https://doi.org/ 10.1175/1520-0493(2002)130<1510:TIOMLI > 2.0.CO;2.

Mesinger, F., and Coauthors, 2006: North American Regional Reanalysis. Bull. Amer. Meteor. Soc., 87, 343-360, https:// doi.org/10.1175/BAMS-87-3-343.

Minder, J. R., T. W. Letcher, L. S. Campbell, P. G. Veals, and W. J. Steenburgh, 2015: The evolution of lake-effect convection during landfall and orographic uplift as observed by profiling radars. Mon. Wea. Rev., 143, 4422-4442, https:// doi.org/10.1175/MWR-D-15-0117.1.

Muller, R. A., 1966: Snowbelts of the Great Lakes. Weatherwise, 19, 248-257, https://doi.org/10.1080/00431672.1966.10544204.

Niziol, T. A., W. R. Snyder, and J. S. Waldstreicher, 1995: Winter weather forecasting throughout the eastern United States. Part IV: Lake effect snow. Wea. Forecasting, 10, 61-77, https://doi.org/ 10.1175/1520-0434(1995)010<0061:WWFTTE > 2.0.CO;2.

Norton, D. C., and S. J. Bolsenga, 1993: Spatiotemporal trends in lake effect and continental snowfall in the Laurentian Great Lakes, 1951-1980. J. Climate, 6, 1943-1956, https://doi.org/ 10.1175/1520-0442(1993)006<1943:STILEA > 2.0.CO;2.

Peace, R. L., Jr., and R. B. Sykes Jr., 1966: Mesoscale study of a lake effect snow storm. Mon. Wea. Rev., 94, 495-507, https://doi.org/ 10.1175/1520-0493(1966)094<0495:MSOALE>2.3.CO;2.

Rodriguez, Y., D. A. R. Kristovich, and M. R. Hjelmfelt, 2007: Lake-to-lake cloud bands: Frequencies and locations. Mon. Wea. Rev., 135, 4202-4213, https://doi.org/10.1175/ 2007MWR1960.1.

Rolph, G., A. Stein, and B. Stunder, 2017: Real-time Environmental Applications and Display System: READY. Environ. Modell. Software, 95, 210-228, https://doi.org/10.1016/ j.envsoft.2017.06.025.

Rose, B. L., 2000: The role of upstream lakes in determining downstream severe lake-effect snowstorms. Ph.D. dissertation, University of Illinois at Urbana-Champaign, 183 pp., https:// dissexpress.proquest.com/dxweb/results.html?QryTxt $=\& B y=$ Rose $\% 2 \mathrm{C}+$ Bruce $+\mathrm{L} . \% 2 \mathrm{C}+\mathrm{Jr} . \&$ Title $=\% 22 \mathrm{The}+$ role + of + upstream + lakes $\% 22 \&$ pubnum $=$.

Scott, R. W., and F. A. Huff, 1996: Impacts of the Great Lakes on regional climate conditions. J. Great Lakes Res., 22, 845-863, https://doi.org/10.1016/S0380-1330(96)71006-7.

Sousounis, P. J., and J. M. Fritsch, 1994: Lake-aggregate mesoscale disturbances. Part II: A case study of the effects on regional and synoptic-scale weather systems. Bull. Amer. Meteor. Soc., 75, 1793-1811, https://doi.org/10.1175/1520-0477(1994)075<1793: LAMDPI>2.0.CO;2. 
, and G. E. Mann, 2000: Lake-aggregate mesoscale disturbances. Part V: Impacts on lake-effect precipitation. Mon. Wea. Rev., 128, 728-745, https://doi.org/10.1175/1520-0493(2000)128<0728: LAMDPV $>2.0 . \mathrm{CO} ; 2$.

Stein, A. F., R. R. Draxler, G. D. Rolph, B. J. B. Stunder, M. D. Cohen, and F. Ngan, 2015: NOAA's HYSPLIT atmospheric transport and dispersion modeling system. Bull. Amer. Meteor. Soc., 96, 2059-2077, https://doi.org/10.1175/ BAMS-D-14-00110.1.

Strommen, N. D., and J. R. Harman, 1978: Seasonally changing patterns of lake-effect snowfall in western lower Michigan. Mon. Wea. Rev., 106, 503-509, https://doi.org/10.1175/1520-0493(1978)106<0503: SCPOLE $>2.0 . C O ; 2$.

Veals, P. G., and W. J. Steenburgh, 2015: Climatological characteristics and orographic enhancement of lake-effect precipitation east of Lake Ontario and over the Tug Hill Plateau. Mon. Wea. Rev., 143, 3591-3609, https://doi.org/10.1175/ MWR-D-15-0009.1.
Villani, J. P., M. L. Jurewicz Sr., and K. Reinhold, 2017: Forecasting the inland extent of lake effect snow bands downwind of Lake Ontario. J. Oper. Meteor., 5, 53-70, https://doi.org/10.15191/ nwajom.2017.0505.

Wiggin, B. L., 1950: Great snows of the Great Lakes. Weatherwise, 3, 123-126, https://doi.org/10.1080/00431672.1950.9927065.

Wilson, J. W., 1977: Effect of Lake Ontario on precipitation. Mon. Wea. Rev., 105, 207-214, https://doi.org/10.1175/1520-0493(1977) 105<0207:EOLOOP > 2.0.CO;2.

Wright, D. M., D. J. Posselt, and A. L. Steiner, 2013: Sensitivity of lake-effect snowfall to lake ice cover and temperature in the Great Lakes region. Mon. Wea. Rev., 141, 670-689, https:// doi.org/10.1175/MWR-D-12-00038.1.

Wrzesien, M. L., M. T. Durand, T. M. Pavelsky, I. M. Howat, S. A. Margulis, and L. S. Huning, 2017: Comparison of methods to estimate snow water equivalent at the mountain range scale: A case study of the California Sierra Nevada. J. Hydrometeor., 18, 1101-1119, https://doi.org/10.1175/JHM-D-16-0246.1. 